\title{
Young people, good life narratives, and sustainable futures: the case of Instagram
}

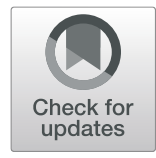

\author{
Anastasia Loukianov ${ }^{*}$ (D), Kate Burningham and Tim Jackson
}

\begin{abstract}
Background: Young people's processes of meaning-making in relation to what it means to live well are supported by the shared understandings of the good life that are available in their particular sociocultural and historical contexts. These understandings are tied to questions of environmental impact and social justice, as each 'good life' entails different levels of material throughput and some may undermine the ability of others to pursue their chosen 'good lives'. This paper draws on the insights from an exploration of Instagram posts tagged \#goodlife to consider the role of Instagram in the constitution of good life narratives that are available to young people. Using network analysis tools, the researchers analyse the relationships between themes of hashtags appearing on 793 posts tagged \#goodlife. The findings from the thematic approach to network analysis are used to support a thematic qualitative exploration of a subsample of 200 of the posts.

Findings: The paper gives an overview of three good life narratives that can be found on the platform: the good life of the self-made affluent entrepreneur, the good life of the world-traveller, the good life as shared experience. Additionally, it highlights the differing levels of popularity of each narrative on the platform, and considers their respective implications for environmental and social sustainability. The paper then provides a conceptual reading of the platform that enables considerations relating to its place in the creation and maintenance of good life narratives. Conceptualising Instagram as a social conversation, the paper suggests that adequate participation on the platform may require engaging in less sustainable practices.

Conclusions: The paper concludes by arguing that while the most popular narratives on the platform are less likely to support sustainable lifestyles, more sustainable understandings of living well are also promoted by users.
\end{abstract}

Keywords: Young people, Instagram, Good life narratives, Sustainability, Shared understandings

\section{Main text}

As humans, we are continually engaged in the process of defining for ourselves and for each other the nature of the good life. But in this search for definitions, we are not entirely free to choose anything we like [19]. Rather, we are supported by the shared understandings of the good life that are available through our particular sociocultural and historical contexts. These understandings play a role in what we believe is the 'right' or 'desirable' way to lead our lives. In this, they constitute potential

* Correspondence: a.loukianov@surrey.ac.uk

University of Surrey, Guildford, UK normative journeys that we can take, some of which are more conducive to sustainable futures than others.

Although this process of definition is ongoing throughout human life, the creation and promotion of understandings that are more conducive to sustainable ways of living is particularly relevant to young people. Environmental impact, growing social inequality, and unstable economies are all challenges linked to our understandings of the good life. While young people had no role in instigating these issues and should not be sole bearers of the responsibility of redressing them, they inherit a world that is shaped by them [30].

In this paper, we explore some of the shared understandings or narratives of the good life that are created 
on Instagram - a social media platform that is popular among young people. We start by briefly introducing the literature around understandings of the good life and justifying the focus on Instagram, before outlining our theoretical stance and methodology. We then present three different good life narratives that are available on Instagram, and through a consideration of the wider context of the platform's use, explore what the prevalence of these narratives may mean for sustainability. While these narratives are not solely created and promoted by young people, they occur in a context that plays a particularly important role in the lives of many of them. We conclude that although the most popular narratives on the platform are less likely to support sustainable lifestyles, more sustainable understandings of living well are also promoted by users.

\section{Background}

This section starts by introducing the theoretical background to this paper before covering the methods used.

\section{Instagram, young people, and sustainable wellbeing}

Human beings always live on the basis of some understanding of what is a life worth striving for - that is to say, the good life [11]. Understandings of the good life have evolved throughout history [29, 34, 49, 58, 72] and differ across societies and cultures [45, 53, 77]. But even within a given contemporary society or culture, multiple understandings co-exist $[45,54]$. The diversity of meanings of living well highlights the social construction of our understandings of the good life. These socially constructed understandings are simultaneously supported by a diverse range of practices that enable their realisation [62] and contribute to bringing their supportive practices into being [27]. The stories that we tell, the concepts that we use, and the metaphors we live by have been shown to play a role in our behaviour $[31,40]$ and in the possibility of sustainable futures [28]. Of course, understandings of the good life are not the sole determinants of a transition to more sustainable living [37], but they both facilitate and constrain such shifts.

For Dean [14], our shared understandings are constructed through discursive practices, in interaction with others and in specific contexts. Meanings of the good life are not settled scripts but matters of constant contestation. The social spaces in which interactions happen shape the creation, maintenance, evolution, and dispute of good life understandings by encouraging certain language and interaction choices while hindering others [25]. Discourse-based studies carried out in relation to young people's understandings of wellbeing highlight the role played by discursive repertoires in enabling understandings [61], the importance of context in making repertoires available [54], and the struggle of establishing understandings [45].
While social media platforms are highly popular among young people [67], making them important spaces of meaning-making, few studies of young people's views on wellbeing consider social media settings [21]. Yet, new media technologies are likely to play a role in shaping ideas about what it means to live a good life, both as mediators in the communication of discourses, but also as they introduce new ways of carrying out existing practices or new practices all together.

Youth wellbeing research typically solicits accounts from young people of what living well means to them and isolates their accounts from those of adults [13, 20, 24, 57, 59]. Yet, Mannay [46] argues that there may be value in accepting that 'meanings are always negotiated, revised and co-constructed' by a multiplicity of actors, both older and younger ([46]: 144). This is particularly relevant to this study, as social media platforms can considerably increase the number of people who we make meanings with, theoretically enabling users to share posts with millions of others. Social media offers an opportunity to explore unsolicited accounts of the good life created by participants of all ages, but in a context that has particular relevance to young people.

In this paper, we focus on the good life discourses or narratives that are created on Instagram. Instagram is an image-sharing social media platform with a user-base of over 1 billion and known to be successful with young people, as close to $38 \%$ of its user-base is estimated to be aged 24 or under [68]. Instagram is used by young people throughout the world, with the United States, Brazil, and India ranking as the three leading countries based on number of users [69]. The platform allows users to post photographs and videos accompanied by captions and hashtags and to engage with each other's content through likes, follows, and comments. Hashtags constitute a userled system of classification and make posts searchable. The posts that are tagged \#goodlife could be understood as contributing to an ongoing, Instagram mediated, normative understanding of what living well can mean. While Instagram posts are neither direct nor authentic reflections of people's ideas about 'the good life', they at once constitute shared resources and inform personal understandings of living well. Given our position on the social construction of understandings of the good life, we do not seek to separate young people's accounts from those of adults. The popularity of the platform makes it an important source of shared meanings that should not be overlooked by those interested in sustainable futures.

\section{The study}

This section first introduces our research goals and elucidates our theoretical stance, before introducing our research material and methods. 


\section{Goals and theoretical stance}

The project aimed to identify good life narratives available through \#goodlife on Instagram, explore processes of meaning-making, and appraise the narratives' respective potentials for supporting sustainable futures. In this, our project paralleled that of scholars in the field of ecolinguistics who carry out critiques of existing discourses against a chosen 'ecosophy' [71]. We considered narratives to offer more sustainable approaches to living well if they promoted ways of living that could be realised within ecological boundaries, had social benefits, and were inclusive.

In the tradition of public sociology [8], we see a role for researchers in contributing more readily to public discourses about what the good life should look like [22, 41]. As Levitas [41] highlights, this entails acknowledging the normativity of sociological work. However, 'while sociologists may legitimately claim particular competence in understanding systemic connections and mapping alternatives, they of course do not have any such claim to superior ethical competence' ([41]: 546). Accordingly, we offer our evaluation of the sustainability potentials of good life narratives as a contribution to an ongoing moral conversation rather than a definitive evaluation.

To accommodate our theoretical stance, we are particularly careful to distinguish between people's personal values and beliefs, and their use of the narratives that we identify. We aim to be critical of the narratives, rather than of their carriers. We consider Instagram users to be responding to the demands of a particular context rather than giving straightforward reflections of their mental states or attitudes [76]. Accordingly, in the second part of the analysis, we elucidate this particular context by giving a conceptual reading of Instagram.

\section{Research material and analysis}

The research material used for this paper has been generated as part of a study of the good life narratives that can be accessed on Instagram through the hashtag \#goodlife. The study involved two types of analysis: a qualitative exploration of 200 Instagram posts tagged \#goodlife, and a network analysis of the relationships between the different hashtags associated with \#goodlife in 793 posts. The qualitative analysis aimed to bring out the different types of discourses used in 'good life' posts and explore user engagement with specific narratives. The network analysis aimed to shed light on relationships between thematic clusters of hashtags.

The dataset that constitutes the basis for this study was harvested on the 10th of October 2018 through Netlytic. ${ }^{1}$ At the time of writing, Instagram counts 17,493,291 posts

\footnotetext{
${ }^{1}$ Netlytic is a free software created by Dr. Anatoliy Gruzd and Philip May (M.A., J.D.) to facilitate data collection for academic purposes. The software can be accessed here: https://www.netlytic.org/
}

tagged \#goodlife. We requested Netlytic to harvest a random sample of 2000 of these posts and limit harvesting to public accounts. The oldest post harvested by Netlytic was created on the 30th of January 2018, and the most recent one on the 10th of October 2018. Most harvested posts were created between September and October 2018. An individual user could have contributed multiple posts to the sample.

For each post, Netlytic harvested the hyperlink, the publication date, the author's username, the caption, the like count, and the potential use of filters. However, Netlytic does not harvest images. Additionally, posts may be tagged \#goodlife in the comments rather than in the caption, in which case Netlytic collects the post but does not provide the corresponding hashtags. Hence the first step upon acquiring the dataset was to manually process the 2000 posts to ensure that the correct images and hashtags were recorded for each post. However, it is not uncommon for users to delete posts, accounts, or switch their account settings to private, and it is considered good practice to remove these posts from datasets, as unavailable posts can be interpreted as a withdrawal of consent [23]. Users may delete their posts if they believe that the posts are not gaining enough attention. As posts typically gain the most attention within the first few hours to a day after being posted, and the manual processing of Instagram posts is time-intensive, only 793 posts were useable. The totality of the remaining posts was used to carry out the network analysis, and a subsample of randomly selected 200 posts was used for the qualitative analysis. The qualitative dataset only contained posts from unique Instagram accounts.

All research material was approached thematically. Thematic analysis is a common approach for identifying and analysing patterns in qualitative data [5]. Its flexibility and compatibility with a wide range of theoretical frameworks and data types [5] enabled us to also extend a thematic approach to our hashtag dataset.

The subsample of 200 Instagram posts was analysed both with regards to the content and the form of the posts. With regards to content, posts were classified into 8 content themes established inductively on the basis of the language and the content of the images used. These were: appreciating/making art, food and drinks, physical activities, luxury items and experiences, entrepreneurial spirit, self, significant others, and travel. They can be understood as aspects that users considered to be important for a good life. A given post could refer to multiple content themes. Posts could present a given content theme in different ways. Alongside content themes, we paid attention to the aesthetics used in a given post. We borrowed Manovich [47] distinction between casual, professional, and designed photography as a starting point for the consideration of aesthetics. We 
do not reproduce Manoviches' characterisation here but invite the reader to refer to his work for further detail. To his three categories, we added that of 'quotes', which corresponded to posts in which a quote (plain or photograph background) figured as the image.

The network analysis was conducted on clusters of hashtags, which were established manually by classifying the hashtags appearing on 793 posts tagged \#goodlife into themes. Relationships were established by identifying the co-appearance of hashtags in posts. Figure 1 provides an illustration of the relationships identified between thematic clusters of hashtags. Thematic clusters are represented by nodes and relationships by edges (lines between nodes). The size of a node represents the number and the frequency of appearance of hashtags classified in the cluster. The thickness of an edge represents the relative strength of a relationship. Three particularly important sets of relationships are identified in yellow, blue, and red. They broadly correspond to the hashtags used in posts classified into the content themes of entrepreneurial spirit, travel, and self respectively.

The thematic clusters identified in the network analysis are not directly equivalent to the content themes. Although some thematic clusters (e.g. travel) contain hashtags that would nearly exclusively appear on posts constituting a given content theme (e.g. travel), other thematic clusters (e.g. Instagram and blogging) do not easily map onto content themes. The network analysis also brings to light themes that are not present in the subsample of 200 posts (e.g. spirituality). In this paper, we use the network analysis in support of our analysis of the subsample, and do not discuss any insights that are not directly relevant (see forthcoming for further detail).

Making an educated guess based on users' personal grids, we tentatively determined the user demographics (age and gender - see Table 1) of the subsample to be broadly in line with existing estimates [68, 70]. In this subsample, posts were contributed by personal accounts, inspiration accounts, and business accounts. Accounts were considered to be personal if users posted their own content without commercial aims. Inspiration accounts were those which posted images that had been found elsewhere for noncommercial purposes. These images were sometimes modified with quotes which may have been added by the user. Accounts were considered to be business accounts if posts had commercial goals. Additionally, users in this sample were diverse in terms of popularity. Some users had under a hundred followers, while others counted slightly over 40, 000 followers. All posts are reproduced with their creators' consent.

Table 2 provides a descriptive summary of the frequencies and aesthetics broken down by the content themes present in the subsample of 200 posts. Narratives emerged when relationships were built between content themes, either on the basis of co-appearance of hashtags, use of particular aesthetics, image contents, or discourses.

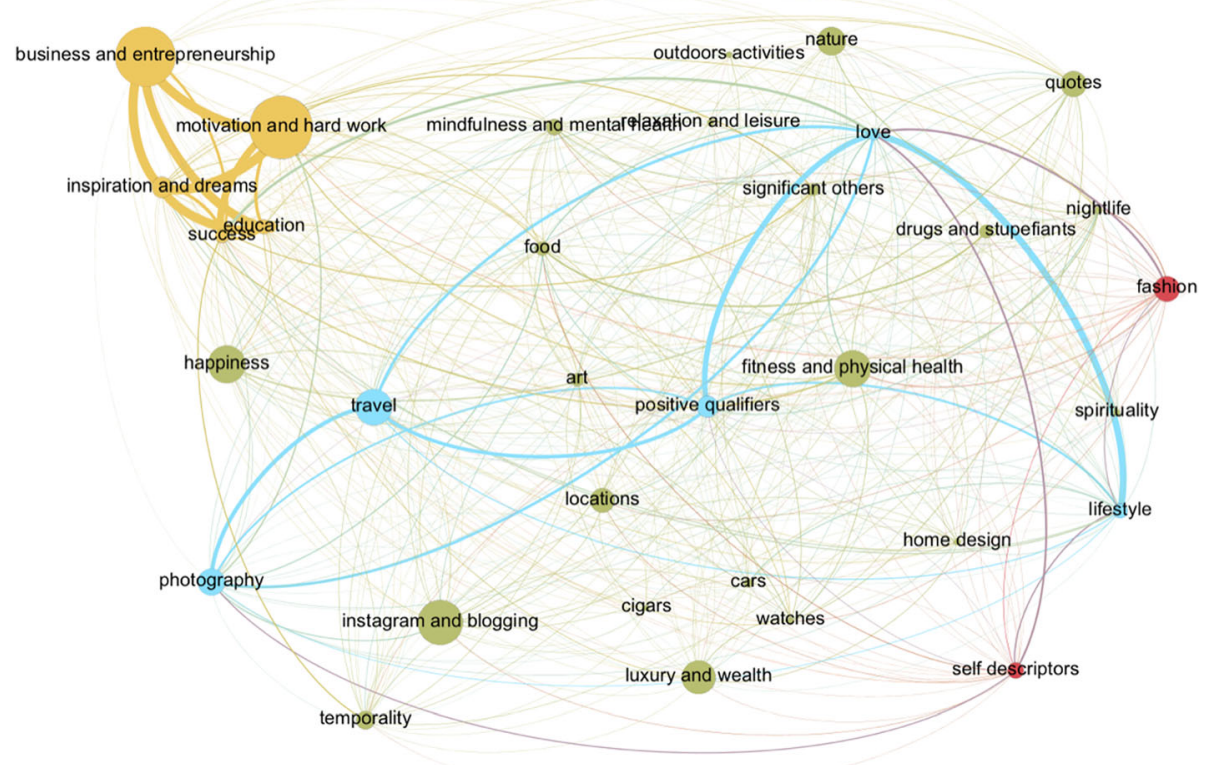

Fig. 1 Plot illustrating the relationships between thematic clusters of hashtags 
Table 1 User demographics for 200 Instagram posts tagged \#goodlife ${ }^{a}$

\begin{tabular}{|c|c|c|c|c|}
\hline $\begin{array}{l}\text { Account type number of posts contributed } \\
\text { to the sample }\end{array}$ & Personal account 158 & Inspiration account 29 & Business account 13 & \\
\hline User inferred gender number of posts & Women 78 & Men63 & Unknown59 & \\
\hline $\begin{array}{l}\text { User estimated age group (in years) } \\
\text { number of posts }\end{array}$ & 25 years old and under 55 & $26-35$ years old 57 & 36 years old and over 29 & Unknown 59 \\
\hline
\end{tabular}

Instagram's Terms and Conditions stipulate that users should be aged 13 and over to legally sign up. However, age is not verified, and it is not uncommon for younger users to sign up.

\section{Good life narratives on Instagram and their potential consequences}

This section presents our findings, beginning with the identification of the narratives and their potentials for delivering sustainable futures, before turning to a conceptual interpretation of Instagram as a social conversation [17].

\section{Three narratives of the good life on Instagram}

We introduce the three good life narratives that emerged in the sample of 200 Instagram posts before considering their respective potentials for delivering sustainable futures, should they serve as guiding stories for what makes a worthwhile life. These narratives were: the good life of the self-made affluent entrepreneur, the good life of the world-traveller, and the good life as shared experience. While overlap is possible between the narratives, we separate them for the sake of clarity.

The good life of the self-made affluent entrepreneur

This narrative appeared in relation to the content themes of physical activities, luxury and wealth, entrepreneurial spirit, and self. Each of these content themes builds

Table 2 Summary table of account type and aesthetics in 200 Instagram posts tagged \#goodlife broken down by content theme

\begin{tabular}{|c|c|c|c|}
\hline Content theme & Number of posts & Account types & Aesthetic \\
\hline \multirow[t]{3}{*}{ Appreciating/making art } & 20 & Business: 3 & Casual photography: 17 \\
\hline & & Inspiration: 1 & Professional photography: 3 \\
\hline & & Personal: 16 & \\
\hline \multirow[t]{3}{*}{ Food and drinks } & 27 & Business: 4 & Casual photography: 17 \\
\hline & & Inspiration: 2 & Designed photography: 6 \\
\hline & & Personal: 21 & Professional photography: 4 \\
\hline \multirow[t]{2}{*}{ Physical activities } & 18 & Personal: 18 & Casual photography: 15 \\
\hline & & Business: 1 & Designed photography: 3 \\
\hline \multirow[t]{4}{*}{ Luxury items and experiences } & 37 & Personal: 17 & Casual photography: 21 \\
\hline & & Inspiration: 14 & Quotes: 2 \\
\hline & & Business: 6 & Professional photography: 11 \\
\hline & & & Designed photography: 3 \\
\hline \multirow[t]{4}{*}{ Entrepreneurial spirit } & 45 & Personal: 30 & Casual photography: 14 \\
\hline & & Inspiration: 13 & Quotes: 23 \\
\hline & & Business: 2 & Professional photography: 5 \\
\hline & & & Designed photographs: 2 \\
\hline \multirow[t]{3}{*}{ Self } & 63 & Personal: 63 & Casual photography: 45 \\
\hline & & & Professional photography: 6 \\
\hline & & & Designed photography: 12 \\
\hline \multirow[t]{4}{*}{ Significant others } & 40 & Personal: 39 & Casual photography: 33 \\
\hline & & & Quotes: 1 \\
\hline & & Inspiration: 1 & Professional photography: 1 \\
\hline & & & Designed photography: 5 \\
\hline \multirow[t]{4}{*}{ Travel } & 48 & Personal: 40 & Casual photography: 32 \\
\hline & & Business: 5 & Professional photography: 4 \\
\hline & & Inspiration: 3 & Designed photography: 11 \\
\hline & & & Quote: 1 \\
\hline
\end{tabular}


relationships to the content theme of entrepreneurial spirit on the basis of co-appearance of hashtags (Fig.1), use of aesthetics, image contents, or discourses.

Users who posted content on entrepreneurship often did so through the use of quotes on the background of pictures of fiction characters such as Tony Stark, Tony Montana, or Leonardo Di Caprio's interpretation of Jordan Belfort in The Wolf of Wall Street, as well as those of successful real-life entrepreneurs such as Elon Musk. These characters are all known for the lavish lifestyles that they lead. Alternatively, users used images of luxury items such as high-end cars as backgrounds to their quotes. Hence, the entrepreneur was constructed as someone who is wealthy and lives lavishly. But the narrative also called forth meritocratic ideals, seen in the archetype of the self-made man incarnated by Belfort, Musk, and Montana, as well as in the hashtags used in these posts (i.e. \#nevergiveup, \#motivated, \#dailygrind, etc.). Many of the hashtags used in posts that conveyed this narrative were provided by a third-party application, Prilaga, that provides thematic hashtags for the maximisation of content exposure. These were particularly popular in relation to the content theme of entrepreneurial spirit, as out of 45 posts in that content theme, 29 used the same set of hashtags (with slight variations) provided by Prilaga:

\section{\#marketing \#successquotes \#network \#dreambig \#leadership \#businessowner \#selfmade \#ambition \#goodlife \#buildyourempire \#prilaga \#keepgoing \#millionaire \#inspiration \#millionairelifestyle \#busi- ness \#motivationalquotes \#motivation \#nevergiveup \#grind \#money \#entrepreneur \#mindset \#dailygrind \#startuplife \#motivated \#entrepreneurship.}

These hashtags referred to meritocratic ideals of the self-made person whose hard work results in success, measured by wealth. The meritocratic mindset was also evident in some of the posts that focused on physical activities. The network analysis showed that the thematic cluster of 'fitness and physical health' co-appeared with 'motivation and hard work' as well as 'inspiration and dreams'. It is among one of the few thematic clusters that sustain a significant ${ }^{2}$ relationship (edge weight $\geq 10$ ) with the yellow clusters (Fig. 1). In those of these posts that were present in the subsample, the emphasis was on the strive towards a fit and muscular ideal, rather than on sensations experienced in sport. The link between this understanding of physical activities and

${ }^{2}$ We qualify relationships of 'significant' if they sustain weights that are relatively stronger than those of other relationships in the sample as identified through incremental increases of the threshold of magnitude [1]. In this paper, we focus on those of these relationships that are also evidenced by the findings of the analysis of the subsample. entrepreneurial spirit was further reinforced by the body types of the people presented as the background in quotes in the entrepreneurial spirit content theme: characters appear fit and muscular. This is particularly salient in the case of images of Elon Musk, as only those images in which he corresponds to the traditional male beauty standards are used.

The links drawn between these different themes contribute to building an idea of the kind of person that would lead this good life. This version of the good life is linked with characteristics that are traditionally masculine. The chosen inspirational characters are also all men, reinforcing the traditional image of the entrepreneur. In the content theme termed self, men tended to favour self-descriptions that presented them either in terms of traditionally masculine physical features (i.e. \#beard, \#biceps, \#triceps, etc.) or mental characteristics linked to achievement (i.e. \#motivated, \#successmindset, \#goaldigger, etc.). These are both congruent with the picture of the entrepreneur that we have painted so far and with existing research indicating that user-produced content on social media tends to conform to traditional gender norms $[15,51]$. The self, both in relation to its physique and to its entrepreneurial endeavours, is seen as a work in progress, and there seems to be an imperative to work on these two aspects. The self was presented as a 'marketable subject' whose best qualities should be sought out and showcased ([54]: 466) and was sometimes talked about in business-like terms. As one quote stated: 'Know your worth. Then add tax'. The need to strive towards continuous improvement in physique and in entrepreneurship was reinforced by the meritocratic mindset that permeates many of these posts.

It is notable that most of the posts that referred to entrepreneurial spirit and to physical activities in such ways were posted by men (Fig.2). While women contributed to these content themes and sometimes used shared hashtags, they also tended to emphasise their femininity and the breaching of a typically male sphere. Hence, this version of the good life, that of the affluent entrepreneur leading a lavish lifestyle, seems to be one that is perpetuated by men rather than women. However little information could be found on what kind of entrepreneurial activities these users led, hence this good life may be more aspirational than actual. This could also explain the high proportion of quotes and borrowed images in relation to entrepreneurial spirit. As Rosenblum [60] explains, stylistic conventions are shaped by economic, technical, political, and social constraints. Style, she says, is not exclusively a product of an autonomous set of shared understandings, but at least partly determined by social organisation. As most users cannot share pictures of themselves engaging in entrepreneurial activities or enjoying a lavish lifestyle, they share borrowed pictures or quotes. 
The environmental impacts of the lavish lifestyle that comes with the figure of the affluent entrepreneur are obvious in terms of their high-material throughput. But the narrative may also be problematic on social bases. The incentives to delay gratification, work hard, and have patience, could be beneficial in a range of fields, but here they are applied to entrepreneurial success measured by wealth and/or to the strive towards a physique epitomising traditionally male standards of beauty. While on the surface, meritocracy appears a fair system where success is obtained from hard work and merit, it has also been described as an ideological weapon that individualises failure and favours a neoliberal elite [44]. Isolated incentives to self-responsibility and agency, without consideration of systemic change, may contribute to maintaining an unfair system. The aesthetic conventions used in this narrative suggest that in practice, the lifestyle of the affluent entrepreneur is accessible to few users. Additionally, posts favoured men with a traditionally masculine physique, further limiting the accessibility of the narrative to a particular subset of the population.

\section{The good life of the world traveller}

This narrative appears in relation to the content themes of food, travel, self, and significant others. Some of these links are identified in the network analysis. The thematic clusters colourised in blue (Fig. 1), namely hashtags related to 'travel', 'photography', 'love', and 'positive qualifiers', co-appear in posts that feature the content theme of travel. Links are also evident with the two clusters in red ('fashion' and 'self-descriptors'). These links are further reinforced by the images used (content and aesthetics) and the captions. Links with the content themes of food and significant others are evidenced in images and captions.

Some of the photographs constituting the content themes of travel and of food used designed aesthetics and it is these that we focus on here. In fact, both content themes shared photographs, as users consumed food in the context of travel. Photographs of a young woman, sitting in front of a table of aesthetically arranged food, holding a cup of coffee, and turning away to admire the view are an archetype of that theme. But food also related to travel in the ways in which place was conceptualised in both themes. Many of the photographs in the travel content theme referred to 'nature' as a specific type of paradise of eternally blue skies and pristine beaches and landscapes that served as a backdrop for the user's activities. Similarly, photographs of food were sometimes depicted on the backdrop of a beautiful landscape (or cityscape).

The subject of these photographs was typically a traditionally beautiful young woman who is fashionable (links with the 'fashion' thematic cluster), and, while money was never mentioned, implicitly well-off. These pictures represent the self under a good light as hashtags also emphasised (\#sexy, \#hairgoals, \#beautiful, \#stylish). Often, as we have noted, the young woman did not look at the camera. This particular genre of photographs resulted in a seemingly candid shot in which the life of the user was staged in a curated mise-en-scène of beautiful backgrounds and delicious foods [47]. The mise-en-scène occasionally included staged relationships with significant others. The depiction of these activities and their framing as 'paradise' on Instagram - although understandable in the context of 'harried' everyday lives [65] contributes to epitomising travel as a fundamental component of the good life.

Contrary to the good life of the entrepreneur, the good life of the world-traveller seems to be, at least to some extent, accessible to Instagram users, as many pictures are posted on personal accounts and represent the user. Additionally, photographs are less centred on material goods and seem to favour experiences instead (to which a certain amount of material goods, such as fashionable clothes and aesthetically pleasing foods, are often necessary). Theoretically, the promotion of experience over material wealth has the potential to be a sustainable approach to what living well could mean [75]. However, the realisation of this potential is unlikely in this case. As increasingly more posts depict sunny vacations in Bali or the Caribbean, exotic travel becomes normalised. Yet, only a small portion of the world population can afford holidays in faraway lands. Additionally, if the typical figure of the good life narrative of the world-traveller is the young woman who corresponds to the traditional beauty standards, many people who do not conform to these characteristics are barred from taking part.

From an environmental perspective, the increase of air travel could potentially be disastrous as planes tend to emit higher levels of greenhouse gases per passenger miles than most other forms of transportation and require carbon-intensive maintenance and fuelling [35]. Although promising potentials of low-material intensity and social democracy, the epitomisation of faraway travel as the ultimate life experience makes it a complementary approach to the materialistic consumer dream. But this narrative is also problematic in relation to its understanding of place. Conceptualising places that correspond to these particular characteristics as paradises that we 'love' runs the risk of obscuring our dependency on places of economic and ecological support that fall short of meeting these criteria [56]. These are often damaged through the establishment and maintenance of such touristic paradise places. Tourist enclaves in Third World countries may provide some support to their economies, but they also contribute to the destruction of 
local habitats and obscure the living conditions of the locals. Instagram tourism photographs have previously been associated with colonial discourses [66], and while this is unlikely to qualify all Instagram images of travel (Smith only analyses a specific subset of those), it further reinforces the problematic aspects of some photographic and touristic engagements with places of 'paradise'.

\section{The good life narrative of shared experiences}

The last narrative manifested in relation to the content themes of self, creative activities, physical activities, food, and significant others. The links here are much more tenuous, perhaps because they have not been established through the use of a shared vocabulary (i.e. hashtags see Fig. 3) or photographic aesthetic. While many photographs corresponding to these themes shared the characteristics of casual photography, these can seldom be singled out as an aesthetic specific to this narrative as casual photography is characteristic of most contemporary photography $[10,47]$. Some tentative links can however be established based on the attitudes that were promoted in these posts, which may be approached through Soper's alternative hedonism [64]. Without necessary opposition to mainstream ideas of the good life or open promotions of sustainable living, these posts seemed to refer to alternative ideas of what living well could mean.
In the content theme of the self, a minority of posts focused on what the user was doing (i.e. hiking, walking, relaxing, etc.) and on how these activities made the user feel (i.e. good, happy, joyful, etc.). These typically only referred to the user's feelings in the captions and hashtags rather than to any personality or bodily characteristics. The decentralisation of the essential physical and mental attributes for a focus on feelings instead shifts the availability of the narrative from a restricted group of people who correspond to favoured particular characteristics of beauty or personality to all. It is however notable that the emphasis on states of mind on Instagram does not necessarily widen the pool of possible acceptable ways of being, as the depiction of negative feelings, or even neutral feelings, is still typically frowned upon [33]. Yet, this shift has the potential to decentralise the individual, particularly as feelings are not only theoretically accessible to all, they could also be shared with others [6].

It is on this basis that we link both physical activities, significant others, and art to this conception of the self. Users who referred to their physical activities in terms of derived feelings also seemed to value them for enabling them to spend quality time with significant others or by themselves. A similar approach can be observed in the case of the engagement or appreciation of creative activities. In these posts, the state of mind of the user, as a result of engagement or appreciation, was also emphasised. Both art and physical activities are potential ways to share
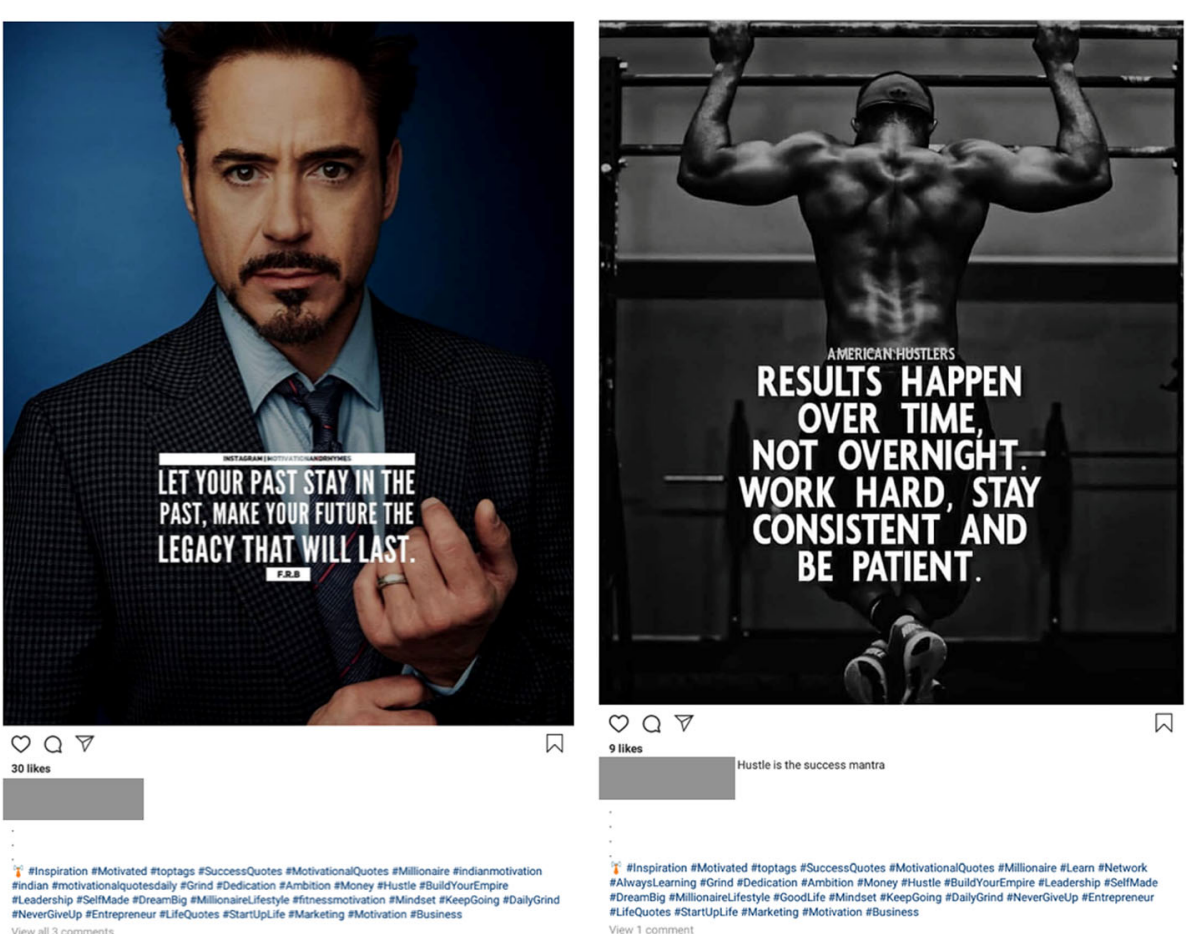

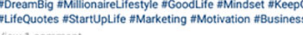
View 1 comment

Fig. 2 Two posts illustrating the good life narrative of the self-made affluent entrepreneur 

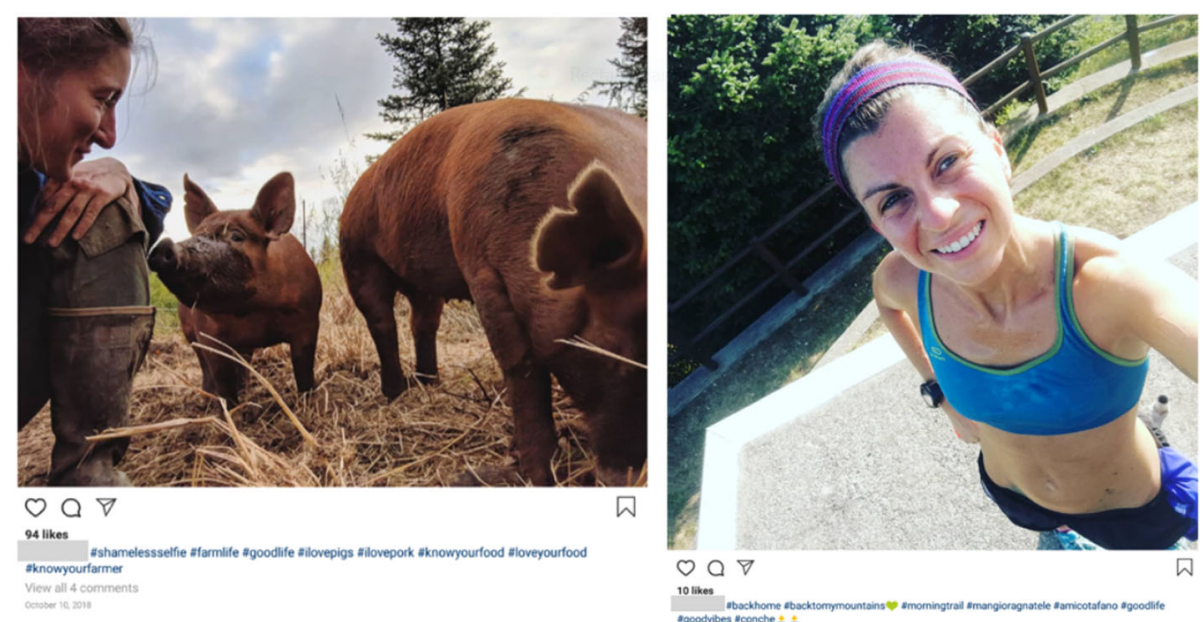

Fig. 3 Two posts illustraying the good life narrative as shared experience

experiences with others. In this context, significant others are celebrated for themselves and for the enjoyment that they bring to shared activities. While in this sample users did not create art with others, they actively sought to engage an audience. Of course, an artist's status is increased through the valorisation of their work, and pleas for the audience to appreciate one's art can be understood as manifestations of narcissism. But they can also be seen as the manifestation of the changing expectations of an artist's work that result in increased pressure on artists to engage viewers on social media [52].

The last link that needs highlighting is that with food, and notably a particular understanding of place that was conveyed in this theme. While the good life narrative of the world-traveller invoked an understanding of place as a backdrop, in this narrative place is understood as the 'root' of food. Understanding place as the origin of sustenance, and by extension the origin of life, enables a consideration of the interconnectedness of humans with their environment. There are obvious environmental benefits from this understanding of place [55].

Additionally, social benefits can be derived from a shared engagement in and enjoyment of activities that have a potential to be sustainable, whether they are physical or creative activities. Crucially, posts that partook in this narrative were created both by men and women, and depicted both men and women. It is notable that spending time with significant others, engaging in creative endeavours, and physical activities have all been highlighted as activities that have the potential to be both low-environmental impact and have potential to contribute to wellbeing [36].

\section{Popularity of good life narratives}

On average, the good life narrative of the successful entrepreneur and that of the world-traveller had most posts with high counts of likes. Indeed, Table 3 shows that both the mean and the median number of likes of posts that conveyed either of these two narratives won more than double the number of likes of posts that conveyed the narrative of shared experience. Additionally, these two narratives had posts with the highest number of likes in the sample. But simply looking at engagement on different posts runs the risk of returning a picture biased by the purchase of likes, followers, and comments. Looking at narratives that appear most often in posts may be a better assessment of the popularity of different good life narratives, bearing in mind that users may be posting content that aligns with the type of content that is already perceived to be popular. The good life narrative of the successful entrepreneur was the most frequent one, followed by that of the worldtraveller. Hence these two narratives were most popular both in terms of engagement and frequency.

\section{The wider context of Instagram good life narratives creation}

This section aims to elucidate the context in which the good life narratives appear by presenting a conceptual reading of Instagram and exploring the place of the platform in narrative creation and maintenance.

\section{Instagram as a social conversation}

Multiple interpretations of Instagram have associated the practice with self-promotion (i.e. [18, 38, 63]). In this paper, we instead suggest a reading that borrows from Douglas and Isherwood's [17] analysis of consumer goods to argue that what happens on the platform is part of a wider social conversation that provides moral judgements on how one ought to live one's life and what ought to be good about it. Under this understanding of Instagram activity, all posts can be seen as contributing 
Table 3 Table of number of total posts and engagement (as determined by number of likes) of the three narratives

\begin{tabular}{lllll}
\hline & Total number of posts & Mean nb of likes per post & Median nb of likes per post & Top three like counts \\
\hline Affluent entrepreneur & 79 & 150 & 63 & 2129 \\
& & & 1221 & 1059 \\
World-traveller & 67 & 167 & 81 & 1314 \\
& & & 359 & 887 \\
Shared experience & 54 & 66 & 38 & 574 \\
& & & & 335 \\
\end{tabular}

to a discussion of what living well means, and how it should be done. For instance, in a study of Instagram posts relating to pregnancy, Tiidenberg and Baym [73] concluded that the posts contributed to defining (and reinforcing) what 'normal' pregnancy should be like and look like. Users who post and engage with Instagram posts contribute to the (re)production and circulation of particular narratives.

Assuming that Instagram is indeed a social conversation, to participate, at minimum, users need to post. But the sheer number of users and the platform design combine to ensure that each post will only be visible for a limited amount of time [9], typically to a rather small circle of people. To have a chance at remaining visible and reaching more viewers, users must obtain more likes and comments than others. This is done through tagging, engaging viewers, but also through the purchase of likes and comments. These are used as a currency. Douglas and Isherwood would call them 'marking services': through the distribution of likes, comments, and followings, users circulate judgement on the validity of the content they are viewing. Being a popular user, gives one more discursive space in the conversation, as the platform's design ensures that these users' posts reach more viewers. In terms of exposure, there is a phenomenon of 'the rich get richer' on Instagram [2].

In the process of commenting, liking, following, users contribute to the sedimentation of particular ways of understanding what living well means. Fixing these meanings is essential to the functioning of society [17]. As earlier family albums contributed both to showing that their owners have the knowledge of which aspects of life should be celebrated and reinforce that these are the ones that should be celebrated [10], so do Instagram posts. Posts can also be used to displace meanings [48] that are too fragile and tenuous to be confronted with reality. The less glamorous aspects of travel or entrepreneurial work are seldom displayed on the platform. While McCracken's theory of meaning displacement was originally conceived in relation to consumer goods, it has also been applied to travel photographs by Belk and Hsiu-Yen [4] and can easily be extended to Instagram images as a whole. McCracken argues that the gap between the ideals to which we aspire and our lived realities must be maintained, or they risk being tarnished.

Alongside the establishment, maintenance, and modification of shared ideals, users' engagement with the platform enables them to help create the social world and find 'a creditable place' in it [16]. As users enter the social conversation by posting content and engaging with others, they also contribute to defining their role in that conversation. In this sample, users sometimes explicitly emphasised the role of their personal pages in crafting their image by titling their personal pages 'my world' (and variants) or including phrases such as 'here you can find a little bit of myself' in their page descriptions.

However, conceptualising Instagram activity in this way does not necessarily suggest that Instagram could supplant or displace consumption, and in this way contribute to sustainability by providing a 'dematerialised' output for social conversations. First, one should be careful to distinguish between digital virtual artifacts (such as Instagram posts), which are immaterial, and digital devices used to access digital information [32]. These devices are material-dense, energy-intensive during use and production phases, and are characterised by a commonly short lifespan. Second, notwithstanding the material intensity of electronic devices, adequately posting on Instagram can require high material throughput, as we explain below.

\section{Participating in social conversations}

The precise effects of good life narratives that are found on Instagram may be difficult to tell. This is notably because it is impossible to isolate media from the range of other information sources that we interact with - so interpretations are established in relation to a variety of objects [12], because different groups of people will interpret the same text differently [43], because contexts of interpretation play a role in the interpretation process [42], and because texts may have unexpected and unintended effects. While this study does not assess the influence that Instagram posts may have on viewers' values or describe the readings that users make, it enables some suggestions as to how participation on the platform may matter. 
To take part, one has to learn the rules of adequate participation on the platform. Participating on Instagram necessitates learning new ways of seeing that enable users to discern 'Instagram-worthy' content [50]. This happens through repeated engagement with the platform that creates an understanding of what kind of content is popular and adequate to be posted. It has been recognised that the use of a consistent vocabulary facilitates the broadcast of narratives, as they tend to be more easily recognised [74]. We can further extend this observation to aesthetics and image contents. Narratives that use consistent vocabulary and imagery are more easily identified. The popularity and consistency of the good life narrative of the entrepreneur, and that of the worldtraveller, reinforce their status as adequate forms of participation. Additionally, the use of a consistent set of hashtags in these posts (yellow, blue, and red thematic clusters - Fig. 1) contributes to physically shaping the discursive space of in favour of these narratives. Hashtags used consistently ensure that a narrative can appear 'en masse' in relation to a wider range of hashtags, effectively carving out a space for that narrative.

The analysis shows that many users participate by posting content that corresponds to the narrative of the entrepreneur and to that of the world-traveller. Posting this type of content does not necessarily indicate an adherence to these values, but it does entail the undertaking of some practical actions. Admittedly, we have shown that, in most cases, the good life narrative of the successful entrepreneur is more aspirational than actual, and that most posts related to entrepreneurship mostly consist in quotes or images borrowed from elsewhere. But that of the world-traveller necessitates a range of paraphernalia including fashionable outfits and transportation to various destinations. Hence to adequately participate users must buy the apparel and travel, because the aesthetic conventions of this narrative require users to post their own images. World-travel involves the consumption of a bundle of goods that is much less sustainable than other bundles of goods are. In the case of exotic travel, that can happen in touristic enclaves, it may also involve the (often unknown) participation in a system of oppression of local inhabitants.

Adequate participation can also have repercussions for the users themselves. For instance, it has been acknowledged that users who aspire to becoming entrepreneurs can be lured by faux-traders into enrolling in binary options trading schemes that are rigged against them [7], or be targeted by predatory multi-level marketing agencies [3]. These predatory schemes are advertised on Instagram by showcasing a 'dream life' that, through hard work, anyone can achieve. But statistics show a different reality. A recent Guardian investigative article reveals that the National Fraud Authority estimates that a staggering $£ 59 \mathrm{~m}$ had been defrauded from UK residents in 2017 from binary options alone. Hence participating on the platform as a 'world-traveller' or a 'successful entrepreneur', can have important consequences in environmental, social, and economic terms.

\section{Who sets the standards of participation?}

We now turn to the question of who sets the standards of adequate participation on Instagram. We have argued, with Douglas and Isherwood [17], that in social conversations, participants who have been judged by others to be skilled participants both provide judgements that tend to hold more value than those of other participants and have more power to direct attention than other participants do. Effectively, being judged as skilful equates to accruing more likes/comments/followers than others. This can be achieved either by being already famous (celebrities such as Emma Watson or Cristiano Ronaldo) or by providing content that is judged by others to be fit to be posted on Instagram. For the second category of users, becoming popular can involve buying likes, comments, and followers, or using hashtags provided by Prilaga. Both categories of popular users are sought after by businesses to advertise their products. It is necessary to emphasise the extent to which external for-profit influences contribute to define the discursive space of the good life on Instagram. Meanings can be derived both from lived and from mediated experiences [19]. The capacity of Instagram posts to mediate understandings of the good life is currently mostly harnessed by businesses because they have the capacity to fund the creative work that underpins participation on the platform.

According to Klear [39], a social media analytics and intelligence platform, in 2018, Instagram influencers posted over 2.1 million sponsored posts on the platform. The wide majority of these was created by Millennial, women, micro-influencers. ${ }^{3}$ These are typically users who have become popular through their Instagram activity rather than celebrities, as celebrities tend to have a much larger follower count. They post in relation to lifestyle, fashion, beauty, travel, food, home design, photography, parenting, fitness and wellness, as well as electronic gadgets. Instagram influencer marketing grew by over $39 \%$ in 2018 [39], suggesting that brands are increasing their share of the discursive space, and their messages are delivered by users whose judgements are more valued than those of others. Indeed, studies have found that influencers are perceived to be more trustworthy than traditional celebrities [26]. As the share of discursive space that is occupied by sponsored content increases, there is a danger that what constitutes

\footnotetext{
${ }^{3} \mathrm{~A}$ user is typically considered to be a micro-influencer if they have between $10 \mathrm{~K}-100 \mathrm{~K}$ followers.
} 
adequate participation will be increasingly dictated by business logics.

\section{Conclusion}

Instagram is popular with young people and occupies an important place in the maintenance of shared meanings supporting social ideals. Through the association of particular images and discourses with the 'good life', the narratives that can be found on Instagram can play a role in young people's definitions of their aspirations and understanding of a worthwhile life. This paper has shown that the two most frequent and popular good life narratives that could be found in this sample of Instagram posts provided less sustainable approaches to living well. Conceptualising Instagram as a social conversation highlights the necessity to pay attention not only to how the conversation shapes the world for others but also what it requires us to do to adequately participate. The predominance of two relatively less sustainable narratives in an important space of meaning-making for young people suggests a challenge to sustainability.

Popular users have more power in setting the standards of 'good participation' and for-profit companies are increasingly making use of this influence by providing financial compensation for online marketing. More sustainable understandings of the good life, such as the narrative of shared experience, do exist on Instagram and seem to be attractive to users. However, the lack of a consistent vocabulary and a distinctive aesthetic convention makes it less identifiable as a resource for meaning-making and as a mode of participation on the platform. Additionally, participation in the creation and maintenance of more sustainable good life narratives lacks the support that for-profit companies grant to the promotion of less sustainable narratives. Perhaps there is a role for organisations that seek to promote sustainability to provide support for existing narratives of a more sustainable the good life and in doing so to valorise users' own participation on the platform.

\section{Acknowledgements}

The authors would like to thank the reviewers who have taken the time to review this manuscript, as well as the guest editors for inviting us to submit for this special issue.

\section{Authors' contributions}

$\mathrm{AL}$ is a PhD student and the main author of the manuscript. $\mathrm{KB}$ and $\mathrm{TJ}$, the supervisors, provided useful help throughout the analysis and writing processes by reviewing the manuscript, commenting on the analysis and suggesting directions in which to take the analysis forward, as well as recommending references. The authors read and approved the final manuscript.

\section{Funding}

There is no funding to declare.

\section{Availability of data and materials}

The dataset used in this research project is not publicly available due to anonymity and privacy concerns.

\section{Ethics approval and consent to participate}

The following research project has been given a favourable ethical opinion by the University of Surrey Ethics Committee. Instagram posts were collected solely from public profiles, without participants' consent. It is common practice to collect posts on public profiles without informing users. Here, these posts are not reproduced and are not archived. The only posts that are reproduced are those for which the authors have obtained informed consent from their creators.

\section{Consent for publication}

Consent for publication and reproduction has been obtained from the users concerned. Posts are reproduced where possible.

\section{Competing interests}

The authors declare that they have no competing interests.

Received: 3 September 2019 Accepted: 16 July 2020

Published online: 05 August 2020

\section{References}

1. Allesina S, Bodini A, Bondavalli C. Secondary extinctions in ecological networks: bottlenecks unveiled. Ecol Model. 2006:194:150-61.

2. Araujo CS, Damilton Corrêa LP, Coito da Silva AP, Prates RO, Meira W. 'It's not just a picture: revealing some user practices in Instagram. In: Proceedings of the 9th Latin American web congress; 2014. https://doi.org/10. 1109/LAWeb.2014.12.

3. BBC. Secrets of the multi-level millionaires: Ellie undercover; 2019. Accessed 09/07/19: https://www.bbc.co.uk/iplayer/episode/p076n2hg/secrets-of-themultilevel-millionaires-ellie-undercover/.

4. Belk R, Hsiu-Yen Y. Tourist photographs: signs of the self. Int J Culture Tourism Hospitality Res. 2011;5(4):345-53. https://doi.org/10.1108/ 17506181111174628

5. Braun V, Clarke V, Hayfield N, Terry G. Thematic analysis. In: Liamputtong P, editor. Handbook of research methods in health social sciences. Singapore: Springer; 2019. p. 843-60.

6. Brinkmann S. Damasio on mind and emotions: a conceptual critique. Nordic Psychology. 2006;58(4):366-80. https://doi.org/10.1027/1901-2276.54.4.366.

7. Brown, S. (2018). 'Fake it till you make it: meet the wolves of Instagram'. The Guardian. Accessed 03/05/19: https://www.theguardian.com/news/2018/ apr/19/wolves-of-instagram-jordan-belmont-social-mediatraders/.

8. Burawoy M. For public sociology. Am Sociol Rev. 2005;70:4-28.

9. Carah N, Shaul M. Brands and Instagram: point, tap, swipe, glance. Mobile Media Commun. 2016;4(1):69-84. https://doi.org/10.1177/ 2050157915598180

10. Chalfen R. Snapshot version of life. Wisconsin: University of Wisconsin Press; 1987.

11. Christopher JC. Situating psychological well-being: exploring the cultural roots of its theory and research. J Couns Dev. 1999;77:141-52.

12. Cobley P. Throwing out the baby: populism and active audience theory. Media Cult Soc. 1994;16:677-87.

13. Darbyshire $P$, MacDougall $C$, Schiller W. Multiple methods in qualitative research with children: more insight or just more? Qual Res. 2005;5(4):417-36.

14. Dean H. Discursive repertoires and the negotiation of well-being: reflections on the WeD frameworks. WeD working paper 4. In: ESRC research group on wellbeing in developing countries. London: London School of Economics; 2003.

15. Döring N, Reif A, Poeschl S. How gender-stereotypical are selfies? A content analysis and comparison with magazine adverts. Comput Hum Behav. 2016; 55(B):955-62. https://doi.org/10.1016/j.chb.2015.10.001.

16. Douglas M. Relative poverty - relative communication. In: Hasley A, editor. Traditions of social policy. Oxford: Basil Blackwell; 1976. p. 197-215.

17. Douglas M, Isherwood B. The world of goods. In: Towards and anthropology of consumption. London: Routledge; 1979

18. Dumas TM, Maxwell-Smith M, Davis JP, Giulietti PA. Lying or longing for likes? Narcissism, peer belonging, loneliness and normative versus deceptive like-seeking on Instagram in emerging adulthood. Comput Hum Behav. 2017;71:1-10. https://doi.org/10.1016/j.chb.2017.01.037.

19. Elliott R, Wattanasuwan K. Brands as symbolic resources for the construction of identity. Int J Advert. 1998;17(2):131-44.

20. Fattore T, Mason J, Watson E. Children's conceptualisation(s) of their wellbeing. Soc Indic Res. 2007;80:5-29. 
21. Fattore T, Fegter $\mathrm{S}$, Hunner-Kreisel C. Introduction to special issue children's understandings of well-being: global and local contexts. Child Indic Res. 2019;12(2):379-83.

22. Fischer $\mathrm{E}$. The good life: aspiration, dignity, and the anthropology of wellbeing. Stanford: Stanford University Press; 2014.

23. Franzke AS, Bechmann A, Zimmer M, Ess C, the Association of Internet Researchers. Internet research: ethical guidelines 3.0; 2020. Online access [09/12/19]: https://aoir.org/reports/ethics3.pdf/.

24. Gabhainn SN, Sixsmith J. Children's understandings of well-being. Dublin: The National Children's Office; 2005.

25. Georgakopoulou A. Small stories research: methods - analysis - outreach. In: De Fina A, Georgakopoulou A, editors. Handbook of Narrative Analysis. Oxford: Wiley-Blackwell; 2015. p. 255-72.

26. Gräve J-F. Exploring the perception of influencers V.S traditional celebrities: are social media stars a new type of endorser? In: Proceedings of the 8th international conference on Social Media \& Society. Toronto, July 28-30, 2017; 2017. https://doi.org/10.1145/3097286.3097322.

27. Griggs S, Howarth D. Discourse and practice: using the power of wellbeing. Evidence Policy. 2011;7(2):213-26.

28. Hajer M, Versteeg W. Imagining the post-fossil city: why is it so difficult to think of new possible worlds? Territory, Politics, Governance. 2019;7(2):122-34.

29. Haybron D. The pursuit of unhappiness: the elusive psychology of wellbeing. Oxford: Oxford University Press; 2008

30. Hayward B. Children, citizenship and environment. In: Nurturing a democratic imagination in a changing world. London/New York: Routledge; 2012.

31. Helne T, Hirvilammi T. The relational conception of wellbeing as a catalyst for the eco social transition. In: Matthies A-L, Närhi K, editors. The Ecosocial transition of societies. The contribution of social work and social policy. Abingdon: Routledge; 2017.

32. Hogg N, Jackson T. Digital media and dematerialisation: an exploration of the potential for reduced material intensity in music delivery. J Ind Ecol. 2008;13(1):127-46.

33. Holowka EM. Chapter 12: between artifice and emotion: the "sad girls" of Instagram. In: Bezio K, Yost K, editors. Leadership, popular culture and social change. New horizons in leadership studies; 2018. p. 183-95. https://doi. org/10.4337/9781785368974.

34. Hyman L. Happiness: understandings, narratives and discourses. Basingstoke: Palgrave Macmillan; 2014.

35. IGES, Aalto University, and D-mat Itd. 1.5-degree lifestyles: targets and options for reducing lifestyle carbon footprints. Technical report. Hayma: Institute for Global Environmental Strategies; 2019. Accessed 08/01/20: https://iges.or.jp/en/pub/15-degrees-lifestyles-2019/en/.

36. Isham A, Gatersleben B, Jackson T. Flow activities as a route to living well with less. Environ Behav. 2019;51(4):431-61.

37. Jackson T. Foreword. In: Hayward B, editor. Children, citizenship and environment. Nurturing a democratic imagination in a changing world. London/New York: Routledge; 2012.

38. Jones $M$, Nash J. Eating ourselves into identity? An investigation into the relationship between dining-out experiences and identity production on Instagram amongst female young professionals. J Promotional Commun. 2017;5(2):156-75.

39. Klear (2019). 'The State of Influencer Marketing 2019. Findings from analysing 2,113,307 Instagram \#ad posts'. Klear. Accessed 03/05/19: https://klear.com/TheStateOfInfluencerMarketing2019.pdf/.

40. Lakoff G, Johnson M. Metaphors we live by. Chicago: University of Chicago Press; 2003.

41. Levitas R. Back to the future: Wells, sociology, utopia and method. Sociol Rev. 2010;58(4):530-47.

42. Livingstone $S$, Das R. The end of audiences?: theoretical echoes of reception amid the uncertainties of use. In: Hartley J, Burgess J, Bruns A, editors. A companion to new media dynamics. Oxford: Wiley-Blackwell; 2013. p. 104-21.

43. Livingstone S. Active audiences? The debate progresses but is far from resolved Commun Theory. 2015;25(4):439-46. https://doi.org/10.1111/comt.12078.

44. Littler J. Meritocracy as plutocracy: the marketing of "equality" under neoliberalism. New Formations: J Culture/Theory/Politics. 2013;(80-81):52-72. https://doi.org/10.3898/NewF.80/81.03.2013.

45. Loera-Gonzalez J. Authorised voices in the construction of wellbeing discourses: a reflective ethnographic experience in northern Mexico. In: White S, Blackmore C, editors. Cultures of wellbeing. Method, place, policy. Basingstoke: Palgrave Macmillan; 2015.

46. Mannay D. Who put that on there... why why why? Power games and participatory techniques of visual data production. Vis Stud. 2013;28(2):136-46.
47. Manovich L. Instagram and contemporary image; 2017. Published online, accessed 03/05/18: http://manovich.net/index.php/projects/instagram-andcontemporary-image/.

48. McCracken G. Culture and consumption: new approaches to the symbolic character of consumer goods and activities. Bloomington: Indiana University Press; 1988.

49. McMahon DM. The pursuit of happiness: a history from the Greeks to the present. London: Penguin Books; 2006.

50. Miller D. Social Media in an English Village. (or how to keep people at just the right distance); 2016. Why We Post 2. Open Access PDF, UCL Press.

51. Miller D, Costa E, Haynes N, McDonald T, Nicolescu R, Sinanan J, et al. How the world changed social media (why we post). London: UCL Press; 2016.

52. Morris JW. Artists as entrepreneurs, fans as workers. Pop Music Soc. 2014; 37(3):273-90. https://doi.org/10.1080/03007766.2013.778534.

53. Ng AK, Ho D, Wong SS, Smith I. In search of the good life: a cultural odyssey in the east and west. Genet Soc Gen Psychol Monogr. 2003;129(4):317-63.

54. O'Flynn G, Bendix Petersen E. The "good life" and the "rich portfolio": young women, schooling and neoliberal subjectification. Br J Sociol Educ. 2007; 28(4):459-72.

55. Plumwood V. Gender, eco-feminism, and the environment. In: White R, editor. Controversies in environmental sociology. Cambridge: Cambridge University Press; 2004. p. 43-60.

56. Plumwood V. Shadow places and the politics of dwelling. Aust Humanit Rev. 2008:44:139-50

57. Pollock G, Ozan J, Goswami H. Chapter 1. Notions of well-being, the state of the child well-being research and the MYWeB project. In: Pollock G, Ozan J, Goswami H, editors. Measuring youth well-being. Cham: Springer International Publishing; 2018.

58. Rabbås $\varnothing$, Emilsson EK, Fossheim $H$, Tuominen $M$. The quest for the good life: ancient philosophers on happiness: Oxford Scholarship Online; 2015. https://doi.org/10.1093/acprof:oso/9780198746980.001.0001/.

59. Redmond G, Skattlebol J, Saunders P, Lietz P, Zizzo G, O'Grady E, et al. Are the kids alright? Young Australians in their middle years. Final report of the Australian child wellbeing project; 2016. Flinders University, University of New South Wales, and Australian Council for Educational Research.

60. Rosenblum B. Style as social process. Am Sociol Rev. 1978;43(3):422-38. https://doi.org/10.2307/2094499.

61. Savahl S, Malcolm C, Slembrouk S, Adams S, Willenberg IA, September R. Discourses on well-being. Child Indic Res. 2015;8(4):747-66.

62. Sayer A. Normativity and naturalism as if nature mattered. J Critical Realism. 2019;18(3):258-73.

63. Sheldon P, Bryant K. Instagram: motives for its use and relationship to narcissism and contextual age. Comput Hum Behav. 2016;58:89-97. https://doi.org/10.1016/j.chb.2015/12.059.

64. Soper K. Re-thinking the "good life": the citizenship dimension of consumer disaffection with consumerism. J Consum Cult. 2007;7(2):205-29.

65. Southerton D. 'Squeezing time' allocating practices, coordinating networks and scheduling society'. Time Soc. 2003;12(1):5-25.

66. Smith SP. Instagram abroad: performance, consumption and colonial narrative in tourism. Postcolonial Studies. 2018;21(2):172-91. https://doi.org/ 10.1080/13688790.2018.1461173.

67. Statista. Age distribution of active social media users worldwide as of $3^{\text {rd }}$ quarter 2014, by platform; 2014. Accessed 07/01/20: https://www.statista.com/statistics/2 74829/age-distribution-of-active-social-media-users-worldwide-by-platform/.

68. Statista. Distribution of Instagram users worldwide as of April 2019, by age group; 2019a. Accessed 03/05/19: https://www.statista.com/statistics/3255 87/instagram-global-age-group/.

69. Statista. Leading countries based on number of Instagram users as of April 2019 (in millions); 2019b. Accessed 03/05/19: https://www.statista.com/ statistics/578364/countries-with-most-instagram-users/.

70. Statista. Distribution of Instagram users worldwide as of April 2019, by gender; 2019c. Accessed 03/05/19: https://www.statista.com/statistics/802 776/distribution-of-users-on-instagram-worldwide-gender/.

71. Stibbe A. An ecolinguistic approach to critical discourse studies. Crit Discourse Stud. 2014;11(1):117-28.

72. Stoll L. A short history of wellbeing research. In: McDaid D, Cooper CL, editors. The Economics of Wellbeing. Wellbeing: A Complete Reference Guide, volume V. Oxford: Wiley-Blackwell; 2014.

73. Tiidenberg K, Baym NK. Learn it, buy it, work it: intensive pregnancy on Instagram. Social Media Soc. 2017:1-13. https://doi.org/10.1177/ 2056305116685108 
74. Waddock S. Narrative, memes, and the prospect of large systems change. Humanist Management J. 2018:3:17-45. https://doi.org/10.1007/s41463-0180039-9.

75. Wallman J. Stuffocation: living more with less. London: Crux Publishing; 2013.

76. Wetherell $\mathrm{M}$, Potter J. Discourse analysis and the identification of interpretative repertoires. In: Antaki C, editor. Analysing everyday explanation. A casebook of methods. London: Sage Publications; 1988

77. Wilmes J, Andresen S. What does "good childhood" in a comparative perspective mean? An exploratory comparison of child well-being in Nepal and Germany. Child Indic Res. 2015;8:33-47.

\section{Publisher's Note}

Springer Nature remains neutral with regard to jurisdictional claims in published maps and institutional affiliations.

Ready to submit your research? Choose BMC and benefit from:

- fast, convenient online submission

- thorough peer review by experienced researchers in your field

- rapid publication on acceptance

- support for research data, including large and complex data types

- gold Open Access which fosters wider collaboration and increased citations

- maximum visibility for your research: over $100 \mathrm{M}$ website views per year

At $\mathrm{BMC}$, research is always in progress.

Learn more biomedcentral.com/submissions 